\title{
Impact of clonal hematopoiesis on outcomes in patients with aplastic anemia
}

\author{
Katarzyna Brzeźniakiewicz-Janus ${ }^{1}$, Joanna Rupa-Matysek ${ }^{2 *}$ (D) Anna Hoppe ${ }^{2}$, Lidia Gil² (D) \\ ${ }^{1}$ Department of Hematology, Faculty of Medicine and Health Science, University of Zielona Gora, Multi-Specialist Hospital Gorzow \\ Wielkopolski, Gorzów Wielkopolski, Poland \\ ${ }^{2}$ Department of Hematology and Bone Marrow Transplantation, Poznan University of Medical Sciences, Poznań, Poland
}

\begin{abstract}
Over the years, not only have the T-cell mediated immune mechanisms of aplastic anemia (AA) involved in AA development started to become better understood, but there is now also a better understanding of the roles played by somatic mutations, cytogenetic abnormalities and defective telomerase functions and other genetically-related factors.

Somatic gene mutations suggestive of clonal hematopoiesis are detected in approximately one third of patients with AA. Recent studies have suggested that some of these may predict a better response to immunosuppressive therapy, whereas others indicate poorer outcomes with higher risks of clonal evolution to myelodysplastic syndrome or acute myeloid leukemia, and that therefore better results may be obtained based on allogeneic stem cell transplantation. Furthermore, recent advances in molecular techniques may be useful in differentiating aplastic anemia from hypocellular myelodysplastic syndrome and other clonal hematopoiesises of indeterminate potential. All of these are summarized in this review which includes further insights into treatment personalization based on the molecular pathogenesis of AA.

Key words: aplastic anemia, clonal hematopoiesis, outcomes, allogeneic stem cell transplantation
\end{abstract}

Acta Haematologica Polonica 2021; 52, 6: 543-551

\section{Introduction}

Aplastic anemia $(\mathrm{AA})$ is a rare form of bone marrow failure caused by autoimmune destruction of hematopoietic progenitor stem cells with a clinical picture dominated by pancytopenia [1, 2].

For many years, it was thought to be based solely on the response of T-cell mediated immune mechanisms to toxic agents, including cytotoxic drugs, some medications, irradiation, toxins or infections such as viruses $[3,4]$. In the majority of cases, some genetic abnormalities are also relevant. In all cases, an extensive differential diagnostic work-up should be performed (Table I) to exclude other pancytopenia causes (Table II) and thus to establish the diagnosis of AA. The appropriate decisions and choices of therapy, along with an assessment of risk stratification, are based on the Camitta classification of AA (Table III) [5-7].

The incidence of AA is, on average, 2 cases per million in Europe. The incidence is roughly three times higher in Asia, which may indicate some genetic or environmental factors [8-11]. Several hypotheses have been proposed to explain why the incidence of AA is higher in Asia than in Europe and North America, but the most probable seems to be host genetics such as HLA types and nucleotide polymorphisms in some cytokine genes [12]. There is no difference in the incidence of $A A$ between men and women, but as most cases are observed before the age of 40 , a genetic predisposition to AA has been suggested. Although clonal evolution of AA to paroxysmal nocturnal hemoglobinuria

\footnotetext{
*Address for correspondence: Joanna Rupa-Matysek, Department of Hematology and Bone Marrow Transplantation, Poznan University of Medical Sciences, Szamarzewskiego 84, 60-569 Poznań, Poland, phone +48 6185493 83, fax +48 6185493 56, e-mail: rupa.matysek@gmail.com
}
PTHiT Copyright (c) 2021
The Polish Society of Haematologists and Transfusiologists, Insitute of Haematology and Transfusion Medicine. All rights reserved.


Table I. Proposed diagnostic procedures for aplastic anemia (AA)

\begin{tabular}{|c|c|}
\hline Category & Tests \\
\hline Peripheral blood testing & $\begin{array}{l}\mathrm{CBC} \text {, differential, reticulocyte } \\
\text { count } \\
\text { Flow cytometry for } \mathrm{PNH}\end{array}$ \\
\hline Bone marrow examination & $\begin{array}{l}\text { Bone marrow smear } \\
\text { Flow cytometry } \\
\text { Cytogenetics } \\
\text { Trephine biopsy }\end{array}$ \\
\hline $\begin{array}{l}\text { Rheumatoid disease } \\
\text { screening }\end{array}$ & $\begin{array}{l}\text { Antinuclear antibodies } \\
\text { Rheumatoid factor }\end{array}$ \\
\hline Liver function tests & ALT, AST, bilirubin serum levels \\
\hline Viral infection testing & $\begin{array}{l}\text { HBV, HCV, EBV, CMV, HHV-6, } \\
\text { HIV, parvovirus B19 }\end{array}$ \\
\hline Visual imaging & $\begin{array}{l}\text { CT, PET-CT, MRI, US for sear- } \\
\text { ching solid tumors and lympho- } \\
\text { proliferative neoplasms }\end{array}$ \\
\hline
\end{tabular}

$\mathrm{CBC}$ - complete blood count; PNH - paroxysmal nocturnal hemoglobinuria; ALT - alanine aminotransferase; AST - aspartate aminotransferase; HBV - hepatitis B virus; HCV - hepatitis C virus; EBV - Epstein-Bárr virus; CMV - cytomegalovirus; HHV-6 - human herpesvirus 6; HIV - human immunodeficiency virus; $\mathrm{CT}$ - computed tomography; PET-CT - positron emission tomography-computed tomography; MRI - magnetic resonance imaging; US - ultrasonography

(PNH), hypocellular myelodysplastic syndrome (MDS) or acute myeloid leukemia (AML) is often observed [13], co-existing somatic mutations may predispose to this process.

Irrespective of the identification of the cause of pancytopenia in the course of $A A$, the responses to immunosuppressive treatment confirm the thesis of autoimmune injury to hematopoietic stem cells and stem cell progenitors [14-16]. The primary role of T-cell cytotoxic lymphocytes along with the additional effect of interferon gamma and tumor necrosis factor (TNF) on the inhibition of hematopoietic stem cell (HSC) production together with an increasing FAS receptor expression (the first sign of apoptosis) all contribute to immune-mediated destruction of HSCs [17-22]. The human leukocyte antigen (HLA) genes play key roles in mediating the immune response, especially HLA class II alleles. A Chinese study identified HLA-DRB1, DQB1 and DPB1 alleles predisposing to AA development [23]. The dysfunction of T regulatory cells is increased NK cells and autoantibodies, which are also involved in HSC immune destruction in AA [24-28].

\section{Inherited bone marrow failure syndromes}

Several genetic disorders including Schwachman-Diamond syndrome (which leads to a reduction in hematopoietic stem cells' ability to repair DNA because of genetic lesions), congenital amegakaryocytic thrombocytopenia (MPL gene), Diamond Blackfan anemia (SBDF gene), Fanconi anemia, some GATA2 spectrum disorders, congenital keratosis,
Table II. Differential diagnosis of aplastic anemia

\begin{tabular}{|l|l|l|}
\hline Infectious diseases & Cancers & Other \\
\hline HBV, HCV & MDS & $\begin{array}{l}\text { Megaloblastic } \\
\text { anemia }\end{array}$ \\
\hline EBV, CMV & AML & PNH \\
HHV-6 & Myelofibrosis & HLH \\
HIV & ALL & \\
\hline Parvovirus B19 & NHL & \\
\hline $\begin{array}{l}\text { Mycobacterial in- } \\
\text { fections }\end{array}$ & HCL & \\
& Solid tumor meta- \\
& stases & \\
\hline
\end{tabular}

HBV - hepatitis B virus; $\mathrm{HCV}$ - hepatitis C virus, EBV - Epstein-Bárr virus; CMV - cytomegalovirus; HHV-6 - human herpesvirus 6; HIV - human immunodeficiency virus; MDS - myelodysplastic syndrome; AML - acute myeloid leukemia; ALL - acute lymphoblastic leukemia; NHL - non-Hodgkin lymphoma; $\mathrm{HCL}$ - hairy cell leukemia; $\mathrm{PNH}$ - paroxysmal nocturnal hemoglobinuria; $\mathrm{HLH}$ - hemophagocytic lymphohistiocytosis

Table III. Camitta criteria for aplastic anemia stratification

\begin{tabular}{|c|c|}
\hline Stage & Criteria \\
\hline $\begin{array}{l}\text { Severe aplastic } \\
\text { anemia (SAA) }\end{array}$ & $\begin{array}{l}\text { Bone marrow cellularity }<25 \% \text { (or } 25- \\
-50 \% \text { with }<30 \% \text { residual hemato- } \\
\text { poietic cells), plus at least two of the } \\
\text { following peripheral blood findings: } \\
\text { - neutrophils }<0.5 \times 10^{9} \\
\text { - platelets }<20 \times 10^{9} / \mathrm{L} \\
\text { - reticulocytes }<20 \times 10^{9} / \mathrm{L}\end{array}$ \\
\hline $\begin{array}{l}\text { Very severe apla- } \\
\text { stic anemia (VSAA) }\end{array}$ & $\begin{array}{l}\text { As SAA, but neutrophils less than } \\
0.2 \times 10^{9} / \mathrm{L}\end{array}$ \\
\hline $\begin{array}{l}\text { Non-severe apla- } \\
\text { stic anemia (NSAA) }\end{array}$ & $\begin{array}{l}\text { Criteria for SAA or VSAA not fulfilled } \\
\text { and decreased bone marrow cellula- } \\
\text { rity, plus at least two of the following } \\
\text { peripheral blood findings: } \\
\text { - neutrophils }<1.5 \times 10^{9} \\
\text { - platelets }<100 \times 10^{9} / \mathrm{L} \\
\text { - hemoglobin }<10 \mathrm{~g} / \mathrm{dL}\end{array}$ \\
\hline
\end{tabular}

SRP72, and congenital pure red cell aplasia have all been identified as familiar cases of AA [29-34]. Careful history-taking and physical examinations may be helpful in the identification of germ-like genetic bone marrow failure disorders associated with $\mathrm{AA}$ and included in differential diagnostics in children, adolescents and young adults (Table IV) [6, 35]. Next-generation sequencing technologies have facilitated the discovery of mutations that cause pancytopenia and lead to aplastic anemia. All of them carry a high risk of MDS/AML, and some of them are associated with an especially high risk of a range of solid tumors. Thus a tailored stem cell transplantation regimen, such as reduced intensity conditioning, may be the optimal treatment. This is especially true for Fanconi anemia, dyskeratosis congenita, Diamond Blackfan anemia, and Shwachman-Diamond syndrome, not only because of the high risk of clonal evolution, but also due to the high risk of morbidity and mortality [36-38]. 
Table IV. Selected anomalies in physical examination indicative of inherited aplastic anemia

\begin{tabular}{|c|c|}
\hline Anomaly & Disease or mutation \\
\hline Short stature & $\begin{array}{l}\text { FA, DKC, DBA, SDS, } \\
\text { SAMD9 }\end{array}$ \\
\hline Microcephaly & FA, DKC \\
\hline Café-au-lait skin lesions & FA \\
\hline $\begin{array}{l}\text { Abnormal skin pigmentation, } \\
\text { dystrophic nail and oral } \\
\text { leucoplakia }\end{array}$ & $\mathrm{DC}$ \\
\hline Skeletal anomalies & SDS \\
\hline $\begin{array}{l}\text { Erythema nodosum, warts } \\
\text { and molluscum }\end{array}$ & GATA2 \\
\hline Absent radii & TARS \\
\hline Abnormal thumbs & FA, DBA \\
\hline Hypertelorism, epicanthal folds & DBA \\
\hline Cerebellar ataxia & SAMD9L \\
\hline
\end{tabular}

\section{Somatic mutations in AA}

Recurrent mutations and variants have been detected in up to $50 \%$ of patients with AA using targeted next generation sequencing hematopoiesis [39-42]. Although some of these mutations are limited to AA, such as PIGA [43] and $B C O R / B C O R L 1$ mutations, others are frequently found in myeloid malignancies, including $A S X L 1$ and DNMT3A. Moreover, DNMT3A-mutated and ASXL1-mutated clones tend to increase in size over time, whereas BCOR- and BCORL1-mutated and PIGA-mutated clones decrease or remain stable [44].

\section{Impact of somatic mutations on outcomes}

Several reports have evaluated the clinical significance of somatic mutations in AA. Firstly, it has been shown that the response to immunosuppressive therapy is better in patients with PIGA, BCOR and BCORL1 mutations [45]. In the study by Hosokawa et al. [45], the presence of increased glycosylphosphatidylinositol-anchored protein-deficient cells correlated with a positive response to immunosuppressive therapy and prognosis, and thus was found helpful in choosing the optimal treatment for trisomy +8 patients with AA or low-risk MD. Although the natural history of AA patients with $\mathrm{PNH}$ clones has been studied, no impact on progression to symptomatic $\mathrm{PNH}$ or transformation to AML/MDS has been observed [46]. Furthermore, higher rates of overall and progression-free survival have been found in these subgroups of mutations [44]. However, other somatic mutations such as DNMT3A and ASXL1 are associated with worse outcomes. Recently, a study into mutation status and the differences between severe and non-severe AA by Patel et al. [47] detected at least one mutation in $19 \%$ of patients with $A A$ at the time of diagnosis, independent of the severity of the AA. However, patients with severe AA had a higher mutation rate compared to moderate AA ( $56 \%$ vs. $19 \%$ ), which corresponds to the unstable hematopoietic clones and higher risk of clonal evolution [47].

Finally, the effect of somatic mutations on a higher risk of progression to MDS/AML was revealed by Kulasekararaj et al. [42]. Furthermore, other specific mutations are likely predictors of secondary MDS [48]. The effect of the therapy applied also influences the mutational status, and BCOR/ /BCORL1 mutations may expand during the course of IST [48]. Negoro et al. demonstrated that, in serial samples of AA without evolution to MDS, clones with GATA2, PHF6, RUNX1, SMC3, TET2 and BCORL1 mutations decreased in size during the course of AA, whereas ASXL1, CALR, CUX1, ETV6, EZH2, G3BP1, RIT1, U2AF1, and ZRSR2 expanded. In contrast, DNMT3A, BCOR, and CEBPA clones showed individually variable behavior with regard to clonal dynamics [48]. Lastly, Negoro et al. [48] also demonstrated the clinical impact of MDS-driver mutations found in AA at presentation, which transformed to MDS and had a shorter median progression-free survival and overall survival compared to cases without such somatic alterations. Other researchers have postulated that clonal dynamics might be highly variable and may not predict response to therapy in individual patients.

\section{Telomerases abnormalities}

Telomere shortening is found in up to $35 \%$ of patients with AA $[49,50]$. It is known that this can result in chromosomal instability and may lead to evolution to MDS/AML [51]. To resist the attrition, germ-like cells utilize telomerase reverse transcriptase (TERT), telomerase RNA component (TERC) telomerase genes, and the stabilizing protein dyskerin (DKC1) to assemble the telomerase complex and maintain telomere length [52]. It has been found that several mutations in TERT, TERC-DKC1 (stabilizing protein dyskerin) and RTEL1 (regulator of telomere elongation helicase 1) are associated with telomere shortening in AA patients $[53,54]$.

Shortened telomere length at diagnosis in patients with AA has been shown to correlate with poorer outcomes [55-57], particularly due to an inadequate response to immunosuppressive therapy. Moreover, some mutations like TERT or TERC mutations $[54,58]$ are associated with transformation to MDS/AML [51, 55, 59, 60]. Sex hormones or other pharmacological agents have been shown to be effective in up-regulating telomere length and reducing the risk of clonal evolution to AML [61]. A frequency of up to $38 \%$ of clonal patterns of $X$-chromosome inactivation in female patients with AA has been observed [62]. 


\section{Cytogenetic abnormalities}

The most common cytogenetic abnormality is monosomy $7(-7)$, occurring in up to $13 \%$ of AA cases. Overall, this is associated with a poorer prognosis and a high risk of progression to MDS or AML [63, 64]. Evaluation of the karyotypes in patients with MDS secondary to AA revealed the presence of chromosomes 6,7 and 8 abnormalities [64] which suggests that these cytogenetic abnormalities, at the initial diagnosis or developed later in patients with AA, can promote progression to MDS/ /AML. Some cytogenetic abnormalities such as trisomy 8 or del $(13 q)$ are associated with a favorable response to immunosuppressive therapy [65-67]. Although they are commonly found in other myeloid malignancies, they are related to a low risk of transformation to MDS or AML $[57,63,68]$. There are many cytogenetic abnormalities whose clinical impact on outcomes remains to be established [69].

\section{Circulating exosomal microRNAs}

MicroRNAs (miRNAs) can regulate T cell differentiation and plasticity by targeting their corresponding message RNAs (mRNAs), which play important roles in many autoimmune diseases and also AA [70-73].

Among several specific miRNAs which regulate RNA silencing and post-transcriptional regulation of gene expression to have been studied in AA and MDS, Guidice et al. [74] identified 25 exosomal microRNAs uniquely or frequently present in AA and/or MDS. One of these, mir-126$-5 p$, with its higher expression at diagnosis in patients with $A A$, was associated with a shorter progression-free survival and a poorer response to therapy. In another study by Hosokawa, two miRNAs were identified: miR-150-5p which regulated the induction of $\mathrm{T}$-cell differentiation, and miR$-146 b-5 p$ which was involved in innate immune response. Both of these increased in AA patients, whereas miR-1 was decreased in AA [75]. Moreover, the elevated expression of miR-150-5p was significantly reduced after successful immunosuppressive therapy but did not change in non-responders, indicating the clinical utility of miR-150-5p for disease monitoring [75].

\section{Management of patients with aplastic anemia}

Prior to initiating treatment for AA, other causes of pancytopenia should be excluded, particularly inherited bone marrow failure syndrome (IBMFS), hypoplastic MDS and some others transient causes of pancytopenia including drugs or infections. As AA may be associated with $\mathrm{PNH}$, detection of the $\mathrm{PNH}$ clone is more indicative for $\mathrm{AA}$ than any other cause of pancytopenia and bone marrow failure. Although allogeneic hematopoietic stem cell transplantation (allo-HSCT) is considered to be the only curative procedure for patients with severe aplastic anemia (SAA), it is recommended that younger patients, particularly children, undergo careful evaluation of concomitant illnesses and performance status to determine unfit or frail patients before intensive therapies, including allo-HSCT or immunosuppressive therapy (IST) [antithymocyte globulin (ATG) or cyclosporine A (CsA)], due to treatment-related mortality and morbidity [76-78]. Figure 1 shows a practical therapeutic algorithm in SAA [European Group for Blood and Marrow Transplantation (EBMT) algorithm for SAA in 2019, modified] [5]. In cases of the detection of clonal hematopoiesis, especially monosomy $7(-7)$ or other abnormalities related to high-risk MDS or insufficient response to IST in patients with SAA below the age of 60, if these patients are assessed as eligible for transplant but have no identical sibling donor, an alternative donor should be sought.

\section{Clonal hematopoiesis and supportive therapy}

All patients with AA require ongoing supportive care to alleviate symptoms and reduce the adverse effects related to pancytopenia. Most studies have reported that infections were the predominant cause of death; therefore recommendations for infection prevention are included in several guidelines, independent of the intensity of AA treatment, both for transplant- or IST-eligible patients and for less fit patients on ongoing supportive care $[6,76$, 79-81].

\section{Granulocyte colony-stimulating factor}

Hematopoietic growth factor, granulocyte colony-stimulating factor (G-CSF) stimulates granulocyte progenitors as well as stem cells for proliferation and differentiation. A randomized prospective trial on patients with newly diagnosed severe AA ( $n=192)$, receiving ATG and cyclosporine, with and without G-CSF, did not demonstrate any impact of G-CSF on the outcome of severe AA, independent of cytogenetic abnormalities. Overall survival and progression-free survival was comparable in both groups, as well as the risk of clonal abnormalities and myeloid neoplasm development [82]. Moreover, the results of a metanalysis of four studies confirm that the usage of G-CSF in IST is not associated with a higher occurrence of clonal evolution into malignant neoplasm and PNH in SAA patients [83]. On the other hand, a rapid granulocyte recovery in patients treated with IST with G-CSF addiction may identify early non-responders, and perhaps indicate the need for urgent transplantation $[84,85]$. 


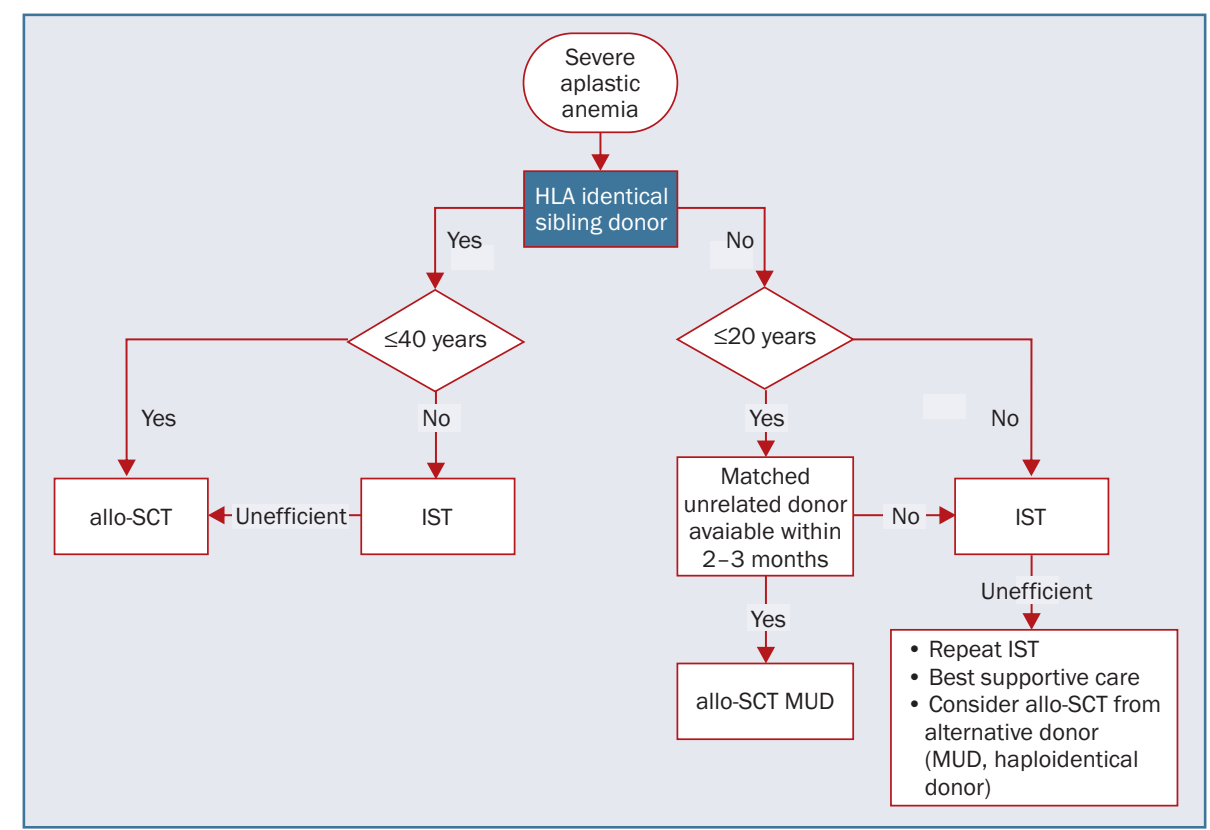

Figure 1. Therapeutic algorithm in severe aplastic anemia; HLA - human leukocyte antigen; allo-SCT - allogeneic stem cell transplantation; IST - mmunosuppressive therapy; MUD - matched unrelated donor

\section{Eltrombopag}

Eltrombopag (EPAG), an oral thrombopoietin (TPO) receptor agonist used in immune thrombocytopenia treatment, is a new therapeutic option in transplant-ineligible SAA patients. The role of TPO in hematopoiesis is not limited only to thrombopoiesis: a TPO receptor C-Mpl is present on hematopoietic stem and progenitor cells (HSPCs), and its lack in murine models leads to HSPC deficiency [86]. EPAG is efficient at SAA refractory to IST and in some patients it restores trilineage hematopoiesis with a sustained response even after discontinuation of the treatment [87-89]. Nevertheless, a risk of clonal evolution during this treatment remains an area of concern. Two prospective studies of EPAG usage in treatment naïve and second in refractory/relapsed SAA have not shown a higher risk of clonal evolution or myeloid neoplasm development compared to historical data $[87,88]$. On the other hand, in phase 1/2 EPAG in R/R SAA (18\%) have developed new cytogenetic abnormalities, most of these (87\%) within six months of beginning treatment. However, some were unstable and disappeared after EPAG withdrawal. Chromosome 7 abnormalities were observed in $8 \%(7 / 83)$ of patients, and four of them had persistent aberration in control cytogenetic testing one month after drug discontinuation. Nevertheless, none of them progressed to MDS/AML [88].

The impact of EPAG on the overall risk of cytogenetic progression, clonal evolution, and/or clinical progression to MDS/AML in patients with SAA requires further investigation. Due to an insufficient response to IST, patients who are platelet transfusion-dependent may receive EPAG as secondary SAA therapy, but its high costs limit the widespread application of this treatment option in many countries $[79,90]$.

\section{Survival after hematopoietic stem cell transplantation}

A recent study demonstrated that in some situations, despite the identification of certain genetic abnormalities of germline monoallelic deleterious variants in the Fanconi anemia gene in patients with idiopathic AA (21 variants in 730 patients), the abnormalities do not influence the outcome of hematopoietic cell transplantation [91].

Generally, although allogeneic HSCT has shown an improvement in survival rates, particularly for HLA-matched unrelated donor transplants, haploidentical transplantation has been proposed as the effective treatment for severe aplastic anemia and it is increasingly being used [15]. The optimal choice of haploidentical donor has also been the subject of research [92]. Furthermore, a recent meta-analysis of 5,336 patients comparing front-line treatments for AA showed significantly longer survival among AA patients undergoing first-line allo-HSCT compared to IST. On the other hand, one of the most important complications after allo-HSCT is graft-versus-host disease, and this needs to be carefully balanced against the concerns of IST [93].

It has to be emphasized that the choice of initial treatment for patients with newly diagnosed AA still requires a comprehensive evaluation of donor availability, patient age, expected quality of life, and the risk of disease relapse or clonal evolution after IST [94]. 


\section{Conclusions}

There are difficulties in differentiating between AA and MDS due to the high prevalence of clonal hematopoiesis in AA with genetic abnormalities overlapping with MDS. Furthermore, a better understanding of the pathogenesis of AA with respect to somatic mutations, cytogenetic abnormalities and defective telomerase functions, and their impacts on the response to IST, along with a balancing of the risk of clonal progression to MDS/AML, may in future allow for treatment personalization with precise indications for upfront allo-HSCT.

\section{Author's contributions}

The authors participated equally in writing the article.

\section{Conflict of interest}

None.

\section{Financial support}

None.

\section{Ethics}

The work described in this article has been carried out in accordance with The Code of Ethics of the World Medical Association (Declaration of Helsinki) for experiments involving humans; EU Directive 2010/63/EU for animal experiments; Uniform requirements for manuscripts submitted to biomedical journals.

\section{References}

1. Maciejewski JP, Selleri C, Sato T, et al. A severe and consistent deficit in marrow and circulating primitive hematopoietic cells (long-term culture-initiating cells) in acquired aplastic anemia. Blood. 1996; 88(6): 1983-1991, indexed in Pubmed: 8822917.

2. Young NS, Calado RT, Scheinberg P. Current concepts in the pathophysiology and treatment of aplastic anemia. Blood. 2006; 108(8): 2509-2519, doi: 10.1182/blood-2006-03-010777, indexed in Pubmed: 16778145.

3. Brown KE, Tisdale J, Barrett AJ, et al. Hepatitis-associated aplastic anemia. N Engl J Med. 1997; 336(15): 1059-1064, doi: 10.1056/ NEJM199704103361504, indexed in Pubmed: 9091802.

4. lavorska I, Nowicki M, Grzelak A, et al. Hepatitis associated aplasic anemia. Acta Haematologica Polonica. 2019; 50(4): 199-203, doi: 10.2478/ahp-2019-0032.

5. de Latour RP, Risitano A, Dufour C. Severe Aplastic Anemia and PNH. In: Carreras E, Dufour C, Mohty M, Kroger N. ed. The EBMT Handbook: Hematopoietic stem cell transplantation and cellular therapies. Springer Open, Cham 2019: 579-585.

6. Killick SB, Bown N, Cavenagh J, et al. British Society for Standards in Haematology. Guidelines for the diagnosis and management of adult aplastic anaemia. Br J Haematol. 2016; 172(2): 187-207, doi: 10.1111/bjh.13853, indexed in Pubmed: 26568159.

7. Young NS. Aplastic Anemia. N Engl J Med. 2018; 379(17): 1643-1656, doi: 10.1056/NEJMra1413485, indexed in Pubmed: 30354958.
8. Incidence of aplastic anemia: the relevance of diagnostic criteria. By the International Agranulocytosis and Aplastic Anemia Study. Blood. 1987; 70(6): 1718-1721, indexed in Pubmed: 3676511.

9. McCahon E, Tang K, Rogers PCJ, et al. The impact of Asian descent on the incidence of acquired severe aplastic anaemia in children. Br J Haematol. 2003; 121(1): 170-172, doi: 10.1046/j.1365-2141.2003.04236.x, indexed in Pubmed: 12670349.

10. Issaragrisil S, Kaufman DW, Anderson T, et al. An association of aplastic anaemia in Thailand with low socioeconomic status. Aplastic Anemia Study Group. Br J Haematol. 1995; 91(1): 80-84, doi: 10.1111/j.1365-2141.1995.tb05248.x, indexed in Pubmed: 7577657.

11. Montané E, Ibáñez L, Vidal X, et al. Catalan Group for Study of Agranulocytosis and Aplastic Anemia. Epidemiology of aplastic anemia: a prospective multicenter study. Haematologica. 2008; 93(4): 518-523, doi: 10.3324/haematol.12020, indexed in Pubmed: 18322256.

12. Kojima S. Why is the incidence of aplastic anemia higher in Asia? Expert Rev Hematol. 2017; 10(4): 277-279, doi: 10.1080/ 17474086.2017.1302797, indexed in Pubmed: 28264622.

13. Socié G, Rosenfeld S, Frickhofen N, et al. Late clonal diseases of treated aplastic anemia. Semin Hematol. 2000; 37(1): 91-101, indexed in Pubmed: 10676914.

14. Scheinberg $P$, Chen J. Aplastic anemia: what have we learned from animal models and from the clinic. Semin Hematol. 2013; 50(2): 156-164, doi: 10.1053/j.seminhematol.2013.03.028, indexed in Pubmed: 24216172.

15. Locasciulli A, Oneto R, Bacigalupo A, et al. Severe Aplastic Anemia Working Party of the European Blood and Marrow Transplant Group. Outcome of patients with acquired aplastic anemia given first line bone marrow transplantation or immunosuppressive treatment in the last decade: a report from the European Group for Blood and Marrow Transplantation (EBMT). Haematologica. 2007; 92(1): 11-18, doi: 10.3324/haematol.10075, indexed in Pubmed: 17229630.

16. Chuncharunee $S$, Wong $R$, Rojnuckarin $P$, et al. Efficacy of rabbit antithymocyte globulin as first-line treatment of severe aplastic anemia: an Asian multicenter retrospective study. Int J Hematol. 2016; 104(4): 454-461, doi: 10.1007/s12185-016-2053-8, indexed in Pubmed: 27376944.

17. Li W, Fu J, Wang F, et al. Distinct overexpression of Fas ligand on T lymphocytes in aplastic anemia. Cell Mol Immunol. 2004; 1(2): 142-147, indexed in Pubmed: 16212902.

18. Zoumbos NC, Gascón P, Djeu JY, et al. Circulating activated suppressor T lymphocytes in aplastic anemia. N Engl J Med. 1985; 312(5): 257 -265, doi: 10.1056/NEJM198501313120501, indexed in Pubmed: 2981406.

19. de Bruin AM, Demirel Ö, Hooibrink B, et al. Interferon-y impairs proliferation of hematopoietic stem cells in mice. Blood. 2013; 121(18): 3578-3585, doi: 10.1182/blood-2012-05-432906, indexed in Pubmed: 23487025.

20. Hosokawa K, Muranski P, Feng $X$, et al. Memory stem $T$ cells in autoimmune disease: high frequency of circulating CD8+ memory stem cells in acquired aplastic anemia. J Immunol. 2016; 196(4): 1568-1578, doi: 10.4049/jimmunol.1501739, indexed in Pubmed: 26764034.

21. Ismail M, Gibson FM, Gordon-Smith EC, et al. Bcl-2 and Bcl-x expression in the CD34+ cells of aplastic anaemia patients: relationship with increased apoptosis and upregulation of Fas antigen. $\mathrm{Br} \mathrm{J}$ Haematol. 2001; 113(3): 706-712, doi: 10.1046/j.1365-2141.2001.02810.x, indexed in Pubmed: 11380462. 
22. Dubey S, Shukla P, Nityanand S. Expression of interferon-gamma and tumor necrosis factor-alpha in bone marrow $\mathrm{T}$ cells and their levels in bone marrow plasma in patients with aplastic anemia. Ann Hematol. 2005; 84(9): 572-577, doi: 10.1007/s00277-005-1022-8, indexed in Pubmed: 15815907.

23. Qi J, Wang TJ, Li HX, et al. Association of HLA class II (-DRB1,-DQB1,-DPB1) alleles and haplotypes on susceptibility to aplastic anemia in northern Chinese Han. Hum Immunol. 2020; 81(12): 685-691, doi: 10.1016/j.humimm.2020.07.001, indexed in Pubmed: 32693929.

24. Liu C, Li Z, Sheng W, et al. Abnormalities of quantities and functions of natural killer cells in severe aplastic anemia. Immunol Invest. 2014; 43(5): 491-503, doi: 10.3109/08820139.2014.888448, indexed in Pubmed: 24661133.

25. Solomou EE, Rezvani K, Mielke S, et al. Deficient CD4+ CD25+ FOXP3+ T regulatory cells in acquired aplastic anemia. Blood. 2007; 110(5): 1603-1606, doi: 10.1182/blood-2007-01-066258, indexed in Pubmed: 17463169.

26. Shi J, Ge M, Lu S, et al. Intrinsic impairment of CD4(+)CD25(+) regulatory T cells in acquired aplastic anemia. Blood. 2012; 120(8): 1624-1632, doi: 10.1182/blood-2011-11-390708, indexed in Pubmed: 22797698.

27. Kordasti S, Marsh J, Al-Khan S, et al. Functional characterization of CD4+ T cells in aplastic anemia. Blood. 2012; 119(9): 2033-2043, doi: 10.1182/blood-2011-08-368308, indexed in Pubmed: 22138514.

28. Smith JNP, Kanwar VS, MacNamara KC. Hematopoietic stem cell regulation by type I and II interferons in the pathogenesis of acquired aplastic anemia. Front Immunol. 2016; 7: 330, doi: 10.3389/fimmu.2016.00330, indexed in Pubmed: 27621733.

29. Sieff $C A$. Introduction to acquired and inherited bone marrow failure. Hematol Oncol Clin North Am. 2018; 32(4): 569-580, doi: 10.1016/j. hoc.2018.04.008, indexed in Pubmed: 30047411.

30. Kirwan M, Walne AJ, Plagnol V, et al. Exome sequencing identifies autosomal-dominant SRP72 mutations associated with familial aplasia and myelodysplasia. Am J Hum Genet. 2012; 90(5): 888-892, doi: 10.1016/j.ajhg.2012.03.020, indexed in Pubmed: 22541560.

31. Ballmaier M, Germeshausen M. Congenital amegakaryocytic thrombocytopenia: clinical presentation, diagnosis, and treatment. Semin Thromb Hemost. 2011; 37(6): 673-681, doi: 10.1055/s-00311291377, indexed in Pubmed: 22102270.

32. McReynolds $\sqcup$, Calvo KR, Holland SM. Germline GATA2 mutation and bone marrow failure. Hematol Oncol Clin North Am. 2018; 32(4): 713-728, doi: 10.1016/j.hoc.2018.04.004, indexed in Pubmed: 30047422.

33. Shen W, Kerr CM, Przychozen B, et al. Impact of germline CTC1 alterations on telomere length in acquired bone marrow failure. $\mathrm{Br}$ J Haematol. 2019; 185(5): 935-939, doi: 10.1111/bjh.15862, indexed in Pubmed: 30891747.

34. Ulirsch JC, Verboon JM, Kazerounian S, et al. The genetic landscape of diamond-blackfan anemia. Am J Hum Genet. 2018; 103(6): 930-947, doi: 10.1016/j.ajhg.2018.10.027, indexed in Pubmed: 30503522.

35. Fox LC, Wood EM, Ritchie DS, et al. Diagnostic evaluation and considerations in hypocellular bone marrow failure-A focus on genomics. Int J Lab Hematol. 2020; 42(Suppl 1): 82-89, doi: 10.1111/ijlh.13179, indexed in Pubmed: 32134198.

36. Shimamura A. Aplastic anemia and clonal evolution: germ line and somatic genetics. Hematology Am Soc Hematol Educ Program. 2016; 2016(1): 74-82, doi: 10.1182/asheducation-2016.1.74, indexed in Pubmed: 27913465.
37. Alter BP. Inherited bone marrow failure syndromes: considerations pre- and posttransplant. Blood. 2017; 130(21): 2257-2264, doi: 10.1182/blood-2017-05-781799, indexed in Pubmed: 29167174.

38. Kallen ME, Dulau-Florea A, Wang W, et al. Acquired and germline predisposition to bone marrow failure: Diagnostic features and clinical implications. Semin Hematol. 2019; 56(1): 69-82, doi: 10.1053/j. seminhematol.2018.05.016, indexed in Pubmed: 30573048.

39. Lane AA, Odejide 0 , Kopp N, et al. Low frequency clonal mutations recoverable by deep sequencing in patients with aplastic anemia. Leukemia. 2013; 27(4): 968-971, doi: 10.1038/leu.2013.30, indexed in Pubmed: 23370706.

40. Heuser M, Schlarmann C, Dobbernack V, et al. Genetic characterization of acquired aplastic anemia by targeted sequencing. Haematologica. 2014; 99(9): e165-e167, doi: 10.3324/haematol.2013.101642, indexed in Pubmed: 24907358.

41. Babushok DV, Perdigones N, Perin JC, et al. Emergence of clonal hematopoiesis in the majority of patients with acquired aplastic anemia. Cancer Genet. 2015; 208(4): 115-128, doi: 10.1016/j.cancergen.2015.01.007, indexed in Pubmed: 25800665.

42. Kulasekararaj AG, Jiang J, Smith AE, et al. Somatic mutations identify a subgroup of aplastic anemia patients who progress to myelodysplastic syndrome. Blood. 2014; 124(17): 2698-2704, doi: 10.1182/ blood-2014-05-574889, indexed in Pubmed: 25139356.

43. DeZern AE, Symons HJ, Resar LS, et al. Detection of paroxysmal nocturnal hemoglobinuria clones to exclude inherited bone marrow failure syndromes. Eur J Haematol. 2014; 92(6): 467-470, doi: 10.1111/ ejh.12299, indexed in Pubmed: 24612308.

44. Yoshizato T, Dumitriu B, Hosokawa K, et al. Somatic mutations and clonal hematopoiesis in aplastic anemia. N Engl J Med. 2015; 373(1): 35-47, doi: 10.1056/NEJMoa1414799, indexed in Pubmed: 26132940.

45. Hosokawa K, Sugimori N, Katagiri T, et al. Increased glycosylphosphatidylinositol-anchored protein-deficient granulocytes define a benign subset of bone marrow failures in patients with trisomy 8. Eur J Haematol. 2015; 95(3): 230-238, doi: 10.1111/ejh.12484, indexed in Pubmed: 25404431.

46. Pu JJ, Mukhina G, Wang H, et al. Natural history of paroxysmal nocturnal hemoglobinuria clones in patients presenting as aplastic anemia. Eur J Haematol. 2011; 87(1): 37-45, doi: 10.1111/j.1600-0609.2011.01615.x, indexed in Pubmed: 21447004.

47. Patel BJ, Barot SV, Kuzmanovic T, et al. Distinctive and common features of moderate aplastic anaemia. Br J Haematol. 2020; 189(5): 967-975, doi: 10.1111/bjh.16460, indexed in Pubmed: 32004386.

48. Negoro E, Nagata Y, Clemente MJ, et al. Origins of myelodysplastic syndromes after aplastic anemia. Blood. 2017; 130(17): 1953-1957, doi: 10.1182/blood-2017-02-767731, indexed in Pubmed: 28893734.

49. Ball SE, Gibson FM, Rizzo S, et al. Progressive telomere shortening in aplastic anemia. Blood. 1998; 91(10): 3582-3592, indexed in Pubmed: 9572992.

50. Brümmendorf TH, Maciejewski JP, Mak J, et al. Telomere length in leukocyte subpopulations of patients with aplastic anemia. Blood. 2001; 97(4): 895-900, doi: 10.1182/blood.v97.4.895, indexed in Pubmed: 11159514.

51. Calado RT. Telomeres and marrow failure. Hematology Am Soc Hematol Educ Program. 2009: 338-343, doi: 10.1182/asheducation-2009.1.338, indexed in Pubmed: 20008219.

52. Calado RT, Young NS, et al. Telomere maintenance and human bone marrow failure. Blood. 2008; 111(9): 4446-4455, doi: 10.1182/ blood-2007-08-019729, indexed in Pubmed: 18239083. 
53. Yamaguchi H, Baerlocher GM, Lansdorp PM, et al. Mutations of the human telomerase RNA gene (TERC) in aplastic anemia and myelodysplastic syndrome. Blood. 2003; 102(3): 916-918, doi: 10.1182/ blood-2003-01-0335, indexed in Pubmed: 12676774.

54. Yamaguchi H, Calado RT, Ly H, et al. Mutations in TERT, the gene for telomerase reverse transcriptase, in aplastic anemia. N Engl J Med. 2005; 352(14): 1413-1424, doi: 10.1056/NEJMoa042980, indexed in Pubmed: 15814878.

55. Scheinberg P, Cooper JN, Sloand EM, et al. Association of telomere length of peripheral blood leukocytes with hematopoietic relapse, malignant transformation, and survival in severe aplastic anemia. JAMA. 2010; 304(12): 1358-1364, doi: 10.1001/jama.2010.1376, indexed in Pubmed: 20858879.

56. Gadalla SM, Wang T, Dagnall C, et al. Association between donor leukocyte telomere length and survival after unrelated allogeneic hematopoietic cell transplantation for severe aplastic anemia. JAMA. 2015; 313(6): 594-602, doi: 10.1001/jama.2015.7, indexed in Pubmed: 25668263.

57. Dumitriu B, Feng X, Townsley DM, et al. Telomere attrition and candidate gene mutations preceding monosomy 7 in aplastic anemia. Blood. 2015; 125(4): 706-709, doi: 10.1182/blood-2014-10-607572, indexed in Pubmed: 25406353.

58. Vulliamy T, Marrone A, Dokal I, et al. Association between aplastic anaemia and mutations in telomerase RNA. Lancet. 2002; 359(9324): 2168-2170, doi: 10.1016/S0140-6736(02)09087-6, indexed in Pubmed: 12090986.

59. Winkler T, Hong SG, Decker JE, et al. Defective telomere elongation and hematopoiesis from telomerase-mutant aplastic anemia iPSCs. J Clin Invest. 2013; 123(5): 1952-1963, doi: 10.1172/JCl67146, indexed in Pubmed: 23585473.

60. Kim SY, Le Rademacher J, Antin JH, et al. Myelodysplastic syndrome evolving from aplastic anemia treated with immunosuppressive therapy: efficacy of hematopoietic stem cell transplantation. Haematologica. 2014; 99(12): 1868-1875, doi: 10.3324/haematol.2014.108977, indexed in Pubmed: 25107891.

61. Calado RT, Yewdell WT, Wilkerson KL, et al. Sex hormones, acting on the TERT gene, increase telomerase activity in human primary hematopoietic cells. Blood. 2009; 114(11): 2236-2243, doi: 10.1182/ blood-2008-09-178871, indexed in Pubmed: 19561322.

62. Mortazavi Y, Chopra R, Gordon-Smith EC, et al. Clonal patterns of $X$-chromosome inactivation in female patients with aplastic anaemia studies using a novel reverse transcription polymerase chain reaction method. Eur J Haematol. 2000; 64(6): 385-395, doi: 10.1034/j.1600-0609.2000.90150.x, indexed in Pubmed: 10901592.

63. Keung YK, Pettenati MJ, Cruz JM, et al. Bone marrow cytogenetic abnormalities of aplastic anemia. Am J Hematol. 2001; 66(3): 167-171, doi:10.1002/1096-8652(200103)66:3<167::aid-ajh1040>3.0.co;2-r, indexed in Pubmed: 11279622.

64. Maciejewski JP, Selleri C. Evolution of clonal cytogenetic abnormalities in aplastic anemia. Leuk Lymphoma. 2004; 45(3): 433-440, doi: 10.1080/10428190310001602363, indexed in Pubmed: 15160903.

65. Saitoh T, Saiki M, Kumagai T, et al. Spontaneous clinical and cytogenetic remission of aplastic anemia in a patient with del(13q). Cancer Genet Cytogenet. 2002; 136(2): 126-128.

66. Ishiyama K, Karasawa M, Miyawaki S, et al. Aplastic anaemia with 13q-: a benign subset of bone marrow failure responsive to immunosuppressive therapy. Br J Haematol. 2002; 117(3): 747-750, doi: 10.1046/j.1365-2141.2002.03518.x, indexed in Pubmed: 12028052.
67. Hosokawa K, Katagiri T, Sugimori N, et al. Favorable outcome of patients who have $13 q$ deletion: a suggestion for revision of the WHO 'MDS-U' designation. Haematologica. 2012; 97(12): 1845-1849, doi: 10.3324/haematol.2011.061127, indexed in Pubmed: 22689682.

68. Boddu PC, Kadia TM. Molecular pathogenesis of acquired aplastic anemia. Eur J Haematol. 2019; 102(2): 103-110, doi: 10.1111/ ejh.13182, indexed in Pubmed: 30380171.

69. Schoettler ML, Nathan DG. The pathophysiology of acquired aplastic anemia: current concepts revisited. Hematol Oncol Clin North Am. 2018; 32(4): 581-594, doi: 10.1016/j.hoc.2018.03.001, indexed in Pubmed: 30047412.

70. LiY, Wan D, Guo R, et al. Decreased bone marrow regulatory innate lymphoid cells show a distinctive miRNA profiling in aplastic anemia. Hematology. 2021; 26(1): 37-42, doi: 10.1080/16078454.2020.1866304, indexed in Pubmed: 33375909.

71. Lu S, Yadav AK, Qiao X. Identification of potential miRNA-mRNA interaction network in bone marrow $T$ cells of acquired aplastic anemia. Hematology. 2020; 25(1): 168-175, doi: 10.1080/ 16078454.2020.1757332, indexed in Pubmed: 32338587.

72. Srivastava J, Chaturvedi CP, Rahman K, et al. Differential expression of miRNAs and their target genes: Exploring a new perspective of acquired aplastic anemia pathogenesis. Int J Lab Hematol. 2020; 42(5): 501-509, doi: 10.1111/ijlh.13245, indexed in Pubmed: 32490599.

73. Bauer M, Vaxevanis $\mathrm{C}$, Heimer $\mathrm{N}$, et al. Expression, regulation and function of microRNA as important players in the transition of MDS to secondary AML and their cross talk to rna-binding proteins. Int J Mol Sci. 2020; 21(19): 7140, doi: 10.3390/ijms21197140, indexed in Pubmed: 32992663.

74. Giudice V, Banaszak LG, Gutierrez-Rodrigues F, et al. Circulating exosomal microRNAs in acquired aplastic anemia and myelodysplastic syndromes. Haematologica. 2018; 103(7): 1150-1159, doi: 10.3324/ haematol.2017.182824, indexed in Pubmed: 29674506.

75. Hosokawa K, Kajigaya S, Feng X, et al. A plasma microRNA signature as a biomarker for acquired aplastic anemia. Haematologica. 2017; 102(1): 69-78, doi: 10.3324/haematol.2016.151076, indexed in Pubmed: 27658437.

76. Peffault de Latour R, Tabrizi R, Marcais A, et al. Nationwide survey on the use of horse antithymocyte globulins (ATGAM) in patients with acquired aplastic anemia: a report on behalf of the French Reference Center for Aplastic Anemia. Am J Hematol. 2018; 93(5): 635-642, doi: 10.1002/ajh.25050, indexed in Pubmed: 29377260.

77. Cesaro S. Progress and trends in pediatric hematopoietic cell transplantation in Central-East European countries. Acta Haematologica Polonica. 2020; 51(3): 119, doi: 10.2478/ahp-2020-0022.

78. Czyżewski K, Sedláček P, Štěrba J, et al. Progress and trends in pediatric hematopoietic cell transplantation in Central-East European countries. Acta Haematologica Polonica. 2020; 51(3): 142-150, doi: 10.2478/ahp-2020-0026.

79. Peffault de Latour R, Huynh L, Ivanova Jl, et al. Burden of illness among patients with severe aplastic anemia who have had insufficient response to immunosuppressive therapy: a multicenter retrospective chart review study. Ann Hematol. 2020; 99(4): 743-752, doi: 10.1007/s00277-019-03809-5, indexed in Pubmed: 32065291.

80. Höchsmann B, Moicean A, Risitano A, et al. Supportive care in severe and very severe aplastic anemia. Bone Marrow Transplant. 2013; 48(2): 168-173, doi: 10.1038/bmt.2012.220, indexed in Pubmed: 23208312.

81. Peslak SA, Olson T, Babushok DV. Diagnosis and treatment of aplastic anemia. Curr Treat Options Oncol. 2017; 18(12): 70, doi: 10.1007/ s11864-017-0511-z, indexed in Pubmed: 29143887. 
82. Tichelli A, Peffault de Latour R, Passweg J, et al. Long-term outcome of a randomized controlled study in patients with newly diagnosed severe aplastic anemia treated with antithymocyte globuline, cyclosporine, with or without G-CSF: a Severe Aplastic Anemia Working Party Trial from the European Group of Blood and Marrow Transplantation. Haematologica. 2020; 105(5): 1223-1231, doi: 10.3324/haematol.2019.222562, indexed in Pubmed: 31582549.

83. Ding SX, Chen T, Wang T, et al. The risk of clonal evolution of granulocyte colony-stimulating factor for acquired aplastic anemia: a systematic review and meta-analysis. Acta Haematol. 2018; 140(3): 141-145, doi: 10.1159/000491816, indexed in Pubmed: 30253387.

84. Bacigalupo A, Oneto R, Schrezenmeier $\mathrm{H}$, et al. First line treatment of aplastic anemia with thymoglobuline in Europe and Asia: outcome of 955 patients treated 2001-2012. Am J Hematol. 2018; 93(5): 643-648, doi: 10.1002/ajh.25081, indexed in Pubmed: 29498107.

85. Bacigalupo A, Bruno B, Saracco P, et al. Antilymphocyte globulin, cyclosporine, prednisolone, and granulocyte colony-stimulating factor for severe aplastic anemia: an update of the GITMO/EBMT study on 100 patients. Blood. 2000; 95(6): 1931-1934, doi: 10.1182/blood.v95.6.1931.

86. Alexander WS, Roberts AW, Nicola NA, et al. Deficiencies in progenitor cells of multiple hematopoietic lineages and defective megakaryocytopoiesis in mice lacking the thrombopoietic receptor c-Mpl. Blood. 1996; 87(6): 2162-2170, indexed in Pubmed: 8630375.

87. Townsley DM, Scheinberg P, Winkler T, et al. Eltrombopag added to standard immunosuppression for aplastic anemia. N Engl J Med. 2017; 376(16): 1540-1550, doi: 10.1056/NEJMoa1613878, indexed in Pubmed: 28423296.

88. Desmond R, Townsley DM, Dumitriu B, et al. Eltrombopag restores trilineage hematopoiesis in refractory severe aplastic anemia that can be sustained on discontinuation of drug. Blood. 2014; 123(12): 1818-1825, doi: 10.1182/blood-2013-10-534743, indexed in Pubmed: 24345753.

89. Olnes MJ, Scheinberg P, Calvo KR, et al. Eltrombopag and improved hematopoiesis in refractory aplastic anemia. N Engl J Med. 2012; 367(1): 11-19, doi: 10.1056/NEJMoa1200931, indexed in Pubmed: 22762314.

90. Lengline E, Drenou B, Peterlin P, et al. Nationwide survey on the use of eltrombopag in patients with severe aplastic anemia: report on behalf of the French Reference Center for Aplastic Anemia. Blood. 2016; 128(22): 2684, doi: 10.1182/blood.v128.22.2684.2684.

91. McReynolds $\sqcup$, Wang $Y$, Thompson AS, et al. Population frequency of fanconi pathway gene variants and their association with survival after hematopoietic cell transplantation for severe aplastic anemia. Biol Blood Marrow Transplant. 2020; 26(5): 817-822, doi: 10.1016/j. bbmt.2020.01.011, indexed in Pubmed: 31982544.

92. Xu LP, Wang SQ, Ma YR, et al. Who is the best haploidentical donor for acquired severe aplastic anemia? Experience from a multicenter study. J Hematol Oncol. 2019; 12(1): 87, doi: 10.1186/s13045-0190775-9, indexed in Pubmed: 31477147.

93. Marsh JCW, Risitano AM, Mufti GJ. The case for upfront HLA-matched unrelated donor hematopoietic stem cell transplantation as a curative option for adult acquired severe aplastic anemia. Biol Blood Marrow Transplant. 2019; 25(9): e277-e284, doi: 10.1016/j. bbmt.2019.05.012, indexed in Pubmed: 31129354.

94. Zhu Y, Gao Q, Hu J, et al. Allo-HSCT compared with immunosuppressive therapy for acquired aplastic anemia: a system review and metaanalysis. BMC Immunol. 2020; 21(1): 10, doi: 10.1186/s12865-0200340-x, indexed in Pubmed: 32138642. 